\title{
A DISCRIMINANT ANALYSIS TO THE QUANTIFICATION OF HUMAN DEVELOPMENT INDEX UNDER ECONOMIC INEQUALITY
}

\author{
Irina GEORGESCU ${ }^{a *}$, Ane-Mari ANDRONICEANU ${ }^{b}$, Jani KINNUNEN ${ }^{c}$ \\ ${ }^{a, b}$ Bucharest University of Economic Studies, Romania \\ ${ }^{c}$ Åbo Akademi University, Finland
}

DOI: $10.24818 / \mathrm{IMC} / 2020 / 05.15$

\begin{abstract}
This paper is concerned with a quantitative approach to the determinants of human development index, namely GDP per capita, Net Income GINI index, Wealth GINI index and poverty rate. For year 2018 and 98 world countries we apply multiple discriminant analysis to predict four classes of human development index. The discriminant analysis achieved $83.7 \%$ accuracy for the discriminant model with unequal apriori probabilities. One conclusion of the model is that GDP per capita has no discriminating power in the model, overall. Another conclusion is that from three discriminant functions retained, the first one discriminates best.
\end{abstract}

KEYWORDS: discriminant analysis, human development index, poverty rate.

\section{INTRODUCTION}

Since its introduction in 1990, the Human Development Index (HDI) has been a measure of progress and human prosperity. HDI is created as a composite index having in the component three dimensions of well-being: life expectancy, education and per capita income indicators. HDI is used to rank world countries into four classes of human development. According to United Nations Human Development Report (2019), HDI is computed as the geometric mean of the three components expressed as indices. In 2014, United Nations introduced fixed cutoff points (COP) in order to determine the four classes of HDI. COPs have been computed using the quartiles of the distributions of the indicators in the composition of HDI averaged during 2004-2013. Thus, COPs are: 0.800 and above- very high human development; 0.700-0.799 - high human development; 0.550-0.699 -medium human development; below 0.550- low human development.

According to Dervis and Klugman (2011), Mura et al. (2019), Bencsik et al. (2019, Haller, 2020), different countries got inspired by the global HDI to use their similar measurements of well-being regionally and nationally (Demirelişçi et al., 2020). For example, US states use their own measure of human development to rank states, districts and ethnic groups. Several states in Latin America, among which Argentina, Brazil, Chile, Mexico (Dervis and Klugman, 2011) use an extended HDI which includes infant mortality rate, quality of education and unemployment rate (Androniceanu, A., Tvaronavičienè, 2019, Ivanisevic et al., 2020). In this context, Bertan (2020) and Ranasinghe (2019) showed that the quality of education is important to doing business in many lines of entrepreneurship (service, tourism and so on).

A country scores a higher HDI if its three composing indices, lifespan, education level and GNI per capita are higher. An alternate measure for HDI is IHDI- Inequality adjusted HDI, introduced by UN in 2010, to measure potential human development. Unlike HDI, IHDI is sensitive to the level of

\footnotetext{
* Corresponding author. E-mail address: irina.georgescu@csie.ase.ro
} 
inequality in each component and is a generalization of HDI (Yalonetzky, 2011; Mishchuk et al., 2018; Vasilyeva et al., 2020).

Development measurement issues remain in focus of various scientists (e.g. Prakash and Garg, 2019; Selivanova-Fyodorova et al. 2019; Meyer and Meyer, 2020; Katekhaye, et al., 2019; Belas et al., 2020).

Georgescu et al. (2020) applied multinomial logistic regression on a set of 98 word stated grouped in four HDI classes according to four explanatory variables: GDP per capita, Net income GINI index, Wealth GINI index and poverty rate for 2018. The conclusions of the research showed that GDP per capita has the least influence on predicting HDI. Income inequality is part of the functioning market economies of the developed countries (Georgescu et al., 2018, 2020; Georgescu \& Kinnunen, 2019, 2020), while wealth inequality in the low income and low HDI countries seemed to be a characteristic of less developed economies with less stable political systems (Kinnunen et al., 2019a, 2019b). This paper is a continuation of Georgescu et al. (2020), where the multinomial logistic regression model achieved a 92.9\% accuracy and R squared values over 0.9.

In this paper we use the same set of countries and the same variables as in the paper by Georgescu et al. 2020 and we discuss the application of another classifier, multiple discriminant analysis (MDA) and its predictive power, taking HDI as the response variable.

\section{DATA AND RESEARCH METHODOLOGY}

In this paper we use data for 98 world countries from World Economic Forum from 2018. The dependent variable is HDI with its four categories: very high HDI (0.8-1), high HDI (0.7-0.799), medium HDI (0.550-0.699) and low HDI (lower than 0.550). We shortly denote the four categories of HDI: 1-low, 2-medium, 3-high, 4-very high. Out of 98 countries, 42 fall into very high category, 27 fall into high category, 15 fall into medium category and 14 into low category. The data is presented in Table 1 . The explanatory variables are GDP per capita, Net income GINI index, Wealth GINI index and poverty rate.

Table 1. Data of HDI categories

\begin{tabular}{|l|c|c|c|c|c|c|}
\cline { 3 - 7 } \multicolumn{2}{c|}{} & HDI & $\begin{array}{c}\text { GDP per } \\
\text { Cap ('000) }\end{array}$ & $\begin{array}{c}\text { Income } \\
\text { Gini }\end{array}$ & $\begin{array}{c}\text { Wealth } \\
\text { Gini }\end{array}$ & $\begin{array}{c}\text { Poverty } \\
\text { Rate }\end{array}$ \\
\hline \multirow{2}{*}{ Very high HDI I } & Avg. & 0.89 & 37715.2 & 32.0 & 68.6 & 7.9 \\
\cline { 2 - 7 } & Std.dev. & 0.05 & 15094.7 & 5.4 & 11.8 & 5.1 \\
\hline \multirow{2}{*}{ High HDI } & Avg. & 0.75 & 12827.8 & 42.2 & 71.8 & 11.0 \\
\cline { 2 - 8 } & Std.dev. & 0.03 & 3910.5 & 7.0 & 12.8 & 10.3 \\
\hline \multirow{2}{*}{ Medium HDI } & Avg. & 0.62 & 4957.5 & 42.0 & 70.6 & 39.7 \\
\cline { 2 - 6 } & Std.dev. & 0.04 & 2093.5 & 5.4 & 11.4 & 20.1 \\
\hline \multirow{2}{*}{ Low HDI } & Avg. & 0.49 & 2254.5 & 37.6 & 67.1 & 75.6 \\
\cline { 2 - 5 } & Std.dev. & 0.05 & 1246.7 & 5.3 & 7.0 & 17.1 \\
\hline
\end{tabular}

Source: own research

Figure 1 plots the distribution of data in each HDI category, rescaled for visualization purposes.

Very High HDI category has the average HDI of 0.89 with the highest GDP per capita of USD 37715 (in 2011 USD in PPP term). The poverty rate and the income Gini are the lowest and wealth Gini the second lowest of the four categories, on average. GDP per capita has larger variance in the top HDI group than in the lower groups.

High HDI category is characterized by the average HDI of 0.75 and GDP per capita of USD 12828, which are the second highest, the income is significantly lower, and also with much lower variance, 
than in the top category. Further, both income and wealth Gini are the highest in this group, while poverty rate is almost as low as in the top HDI category.

Medium HDI category has average HDI of 0.62 and GDP per capita of USD 4958. The income is less than half of the high HDI category with a low variance over the countries in this group. Income and wealth Gini almost at the same level as in high HDI group, but poverty rate is much higher, on average, however, with a very large variability.

Low HDI category has the lowest HDI and income, 0.49 and USD 2255, respective. Income is again less than half of the second lowest (medium) HDI countries, on average. Wealth Gini is the lowest and wealth Gini second lowest of the categories, i.e. citizens are equally poor with the very high poverty rate of $76 \%$, on average.

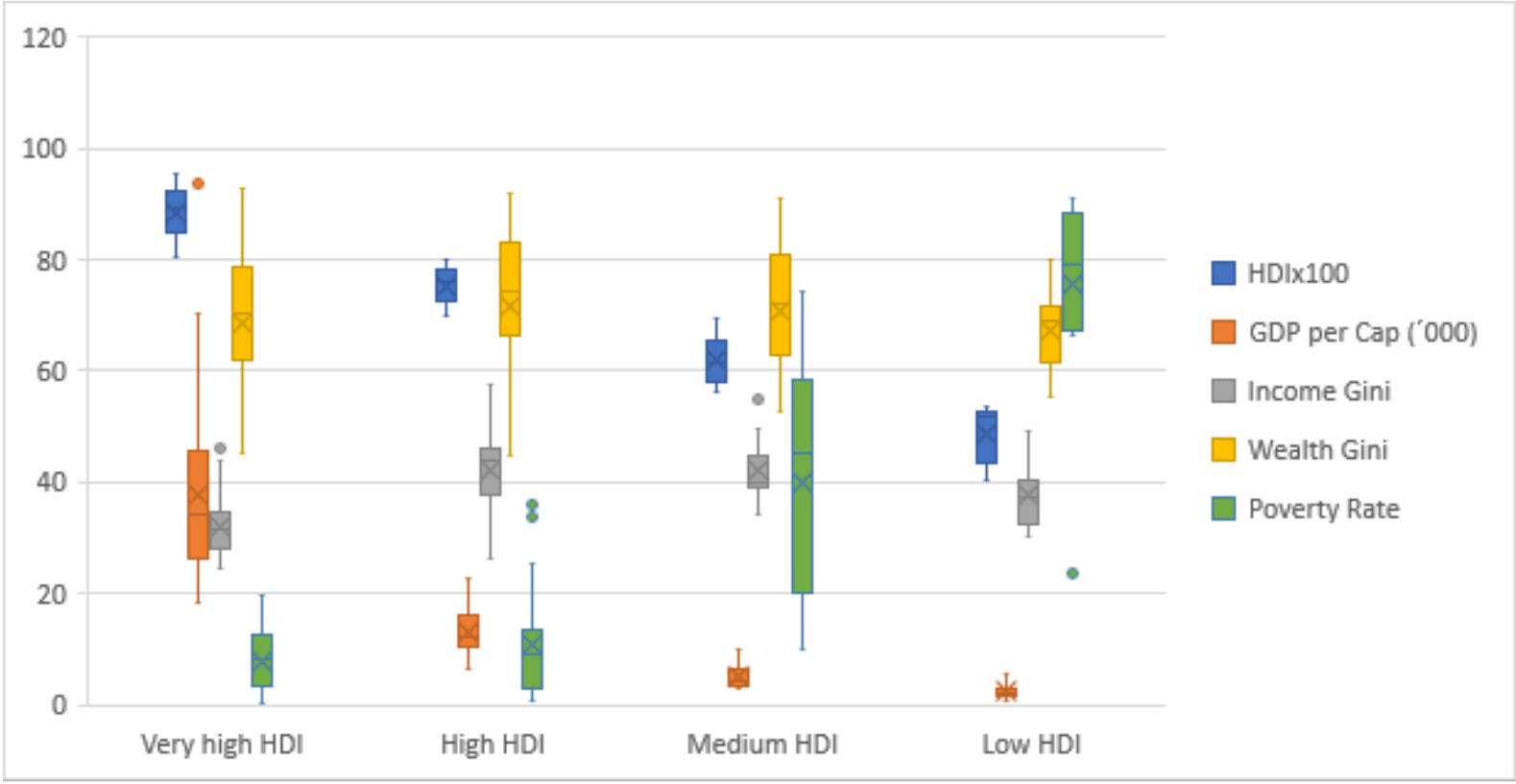

Figure 1. Distribution of inequalities in HDI categories

Source: own research

The purpose of the applied Multiple Discriminant Analysis, MDA, is to examine the differences between the groups of dependent variables and to build a predictive model based on discriminant functions, used for classification of new cases. One discriminant function or more are computed as linear combinations of the predictors that will discriminate best among the groups. The model is based on setting a weight for each variable in the component of the discriminant functions, with the purpose to maximize the between-group variance relative to the within-group variance (Walde, 2014).

We want to find the best discrimination between groups and to eliminate variables less related to group separation.

The assumptions of MDA are:

a) linearity,

b) noncollinearity,

c) the predictors follow a multivariate normal distribution, and

d) the within-group variance-covariance matrices should be equal.

Noncollinearity means that predictors are not highly correlated. Since we have only four predictors, we consider that all predictors can enter the discriminant equation at the same time, therefore we will apply the simultaneous estimation with IBM SPSS v 20. 


\section{MULTIPLE DISCRIMINANT ANALYSIS}

In this section the data analysis and output intepretations follow Bian (2012) and Hans-Vaughn (2017).

In Table 2 the MDA dependent variable HDI is considered the one-way ANOVA independent variable and the MDA independent variables GDP per Capita (PPP2011), Income Gini, Wealth Gini, Poverty Rate are considered the one-way ANOVA outcomes. The last column of Table 2, the F-test value indicates the potential of each predictor in the MDA model. It seems that Wealth Gini does not contribute to the model, since 0.546>0.05. Small values of Wilk's Lambda in the first column of Table 2 show that the corresponding predictors have more potential to discriminate. Wealth Gini has the least discriminatory power, with the highest value of Wilk's Lambda 0,978.

Table 2. ANOVA table

Tests of Equality of Group Means

\begin{tabular}{|l|c|c|c|c|c|}
\hline & Wilks' Lambda & F & df1 & df2 & Sig. \\
\hline GDPperCap(PPP2011) &, 320 & 66,548 & 3 & 94 &, 000 \\
Income Gini &, 629 & 18,490 & 3 & 94 &, 000 \\
Wealth Gini &, 978 &, 715 & 3 & 94 &, 546 \\
Poverty Rate &, 190 & 133,323 & 3 & 94 &, 000 \\
\hline
\end{tabular}

Source: own computations

Table 3 shows the within-group correlation matrix, describing the correlations between predictors. Values greater than 0.90 in absolute value suggest multicollinearity. In Table 3, all correlation coefficients are less than 0.90 , showing that the hypothesis of noncollinearity has been fulfilled.

Table 3. Correlation Matrix Pooled Within-Groups Matrices

\begin{tabular}{|ll|c|c|c|c|}
\hline & & $\begin{array}{c}\text { GDPperCap(PP } \\
\text { P2011) }\end{array}$ & Income Gini & Wealth Gini & Poverty Rate \\
\hline \multirow{6}{*}{ Correlation } & GDPperCap(PPP2011) & 1,000 &,- 268 &, 166 &, 056 \\
& Income Gini &,- 268 & 1,000 &, 379 &, 274 \\
& Wealth Gini &, 166 &, 379 & 1,000 &, 224 \\
& Poverty Rate &, 056 &, 274 &, 224 & 1,000 \\
\hline
\end{tabular}

Source: own computations

Next we refer to Box's test of equality of covariance matrices. In table 4, the larger the log determinant, the more that group's covariance matrix differs from others. The rank column indicates the number of independent variables for each class. MDA assumes homogeneity of covariance matrices between groups, therefore we want to see relatively equal determinants. The log determinants in Table 4 differ mostly between group 1 (HDI =low) and group 4 (HDI= very high).

Table 4. Log determinants

\begin{tabular}{|l|c|c|}
\hline \multicolumn{1}{|c|}{ HDI } & Rank & Log Determinant \\
\hline 1 & 4 & 26,173 \\
2 & 4 & 28,051 \\
3 & 4 & 29,237 \\
4 & 4 & 30,280 \\
Pooled within-groups & 4 & 31,492 \\
\hline
\end{tabular}

Source: own computations 
Table 4 is closely connected to Table 5 . In Table 5, Box's M is a parametric test for checking the null hypothesis of equal covariances across groups. In our case this assumption is violated since $\mathrm{p}=0.000<0.05$.

\section{Table 5. Test results}

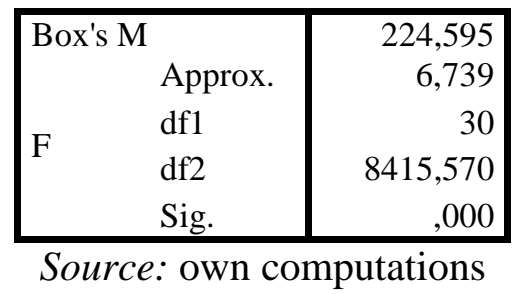

Tables 6 and 7 contain a summary of canonical discriminant functions. HDI has 4 classes, therefore we have 3 functions. The larger the eigenvalue, the more of the variance in the dependent variable HDI is explained by the discriminant function and the bigger the discrimination between groups. Also, the larger the eigenvalue, the greater the discrimination between groups. The greatest eigenvalue 6.346>1 tells us that the first group (HDI=low) and the last group (HDI=very high) have the highest discrimination.

The canonical correlation measures the relation between the discriminant function and the dependent variable HDI. Because we have 4 groups, more than 2, the canonical correlation is the most useful measure. The squared canonical correlation is an effect size for the individual discriminant function. In Table 5, the squared canonical correlation for the first discriminant function is $0,929^{2}=0,863$; for the second discriminant function is $0,724^{2}=0,525$; for the third discriminant function it is $0,028^{2}=0,000784$.

Cohen (Cohen1988, p. 40) proposed some subjective standards for interpreting the effect size: 0.2 small effect; 0.5- medium effect; 0.8- large effect. In accordance with Cohen's standards, the effect size of the first discriminant function is large, of the second is medium and for the third there is no effect. In table 6 the first discriminant function explains nearly all the variance, 85,2\% The second discriminant function explains $14,8 \%$. The third discriminant function can be ignored.

Table 6. Eigenvalues

\begin{tabular}{|c|c|c|c|c|}
\hline Function & Eigenvalue & \% of Variance & Cumulative \% & $\begin{array}{c}\text { Canonical } \\
\text { Correlation }\end{array}$ \\
\hline 1 & $6,346^{\mathrm{a}}$ & 85,2 & 85,2 &, 929 \\
2 & $1,100^{\mathrm{a}}$ & 14,8 & 100,0 &, 724 \\
3 &, $001^{\mathrm{a}}$ &, 0 & 100,0 &, 028 \\
\hline
\end{tabular}

Source: own computations

In Table 7, Wilks' lambda checks how well each discriminant function separates classes. Small values of Wilk's lambda indicate a greater discriminatory power of the associated function.

The p-value (Sig column) from table 7 show the extent to which the four predictors statistically discriminate between groups.

The test of the third function has the p- value 0,965 , so this function contributes less to the model.

Table 7. Wilks' Lambda

\begin{tabular}{|l|c|c|c|c|}
\hline Test of Function(s) & Wilks' Lambda & Chi-square & df & Sig. \\
\hline 1 through 3 &, 065 & 254,518 & 12 &, 000 \\
2 through 3 &, 476 & 69,060 & 6 &, 000 \\
3 &, 999 &, 071 & 2 &, 965 \\
\hline
\end{tabular}

Source: own computations 
The standardized coefficients in Table 8 indicate the relative importance of the four predictors in predicting HDI. Coefficients with larger absolute values correspond to variables with greater discriminatory power. Overall, GDP per capita has the most predictive ability, while WealthGini has the lowest discriminatory ability.

Table 8. Standardized Canonical Discriminant Function Coefficients

\begin{tabular}{|l|r|r|r|}
\hline \multirow{2}{*}{} & \multicolumn{3}{|c|}{ Function } \\
\cline { 2 - 4 } & \multicolumn{1}{|c|}{1} & \multicolumn{1}{c|}{ 2 } \\
\hline GDPperCap(PPP2011) &,- 604 &, 610 &, 662 \\
Income Gini &,- 272 &,- 570 &, 926 \\
Wealth Gini &,- 019 &,- 126 &,- 192 \\
Poverty Rate &, 922 &, 457 &, 235 \\
\hline
\end{tabular}

Source: own computations

Table 9 shows the Pearson correlation between predictors and standardized canonical discriminant functions. Loadings smaller than 0.3 may be removed from the model. Thus PovertyRate has the strongest positive influence on the first canonical discriminant function (0.809), GDP per capita the strongest positive influence on the second discriminant function (0.768), while Income Gini and Wealth Gini have an influence on the third canonical function $(0.741,0.322)$.

Table 9. Structure Matrix

\begin{tabular}{|l|r|r|r|}
\hline & \multicolumn{3}{|c|}{ Function } \\
\cline { 2 - 4 } & \multicolumn{1}{|c|}{1} & \multicolumn{1}{|c|}{ 2 } & \multicolumn{1}{c|}{3} \\
\hline Poverty Rate & $\mathbf{, 8 0 9}$ &, 307 &, 484 \\
GDPperCap(PPP2011) &,- 482 &, $\mathbf{7 6 8}^{*}$ &, 395 \\
Income Gini &, 136 &,- 656 &, $\mathbf{7 4 1}$ \\
Wealth Gini &,- 016 &,- 138 &, $\mathbf{3 2 2}^{*}$ \\
\hline
\end{tabular}

Source: own computations

Table 10. Canonical Discriminant Function Coefficients

\begin{tabular}{|l|r|r|r|}
\hline \multirow{2}{*}{} & \multicolumn{3}{|c|}{ Function } \\
\cline { 2 - 4 } & \multicolumn{1}{c|}{1} & \multicolumn{1}{c|}{2} & \multicolumn{1}{c|}{3} \\
\hline GDPperCap(PPP2011) &, 000 &, 000 &, 000 \\
Income Gini &,- 045 &,- 095 &, 154 \\
Wealth Gini &,- 002 &,- 011 &,- 017 \\
Poverty Rate &, 078 &, 038 &, 020 \\
(Constant) & 1,188 & 2,177 & $-6,337$ \\
\hline
\end{tabular}

Source: own computations

Based on Table 10, we can write the discriminant function equations:

D1=1,188-0,045 Income Gini-0,002 Wealth Gini+0,078 Poverty Rate

D2=2,177-0,095 Income Gini-0,011 Wealth Gini+0,038 Poverty Rate

D3=-6,337+0,154 Income Gini-0,017 Wealth Gini+0,020 Poverty Rate

We notice that GDP per capita has no discriminating power in the model, overall.

Prior probabilities from Table 11 are used for classification. They represent the probabilities that a sample of a group will be sent to a classifier. 
Table 11. Prior Probabilities for Groups

\begin{tabular}{|c|c|c|c|}
\hline HDI & Prior & \multicolumn{2}{|c|}{ Cases Used in Analysis } \\
\hline & & Unweighted & Weighted \\
\hline 1 &, 143 & 14 & 14,000 \\
\hline 2 &, 153 & 15 & 15,000 \\
\hline 3 &, 265 & 26 & 26,000 \\
\hline 4 &, 439 & 43 & 43,000 \\
\hline Total & 1,000 & 98 & 98,000 \\
\hline \multicolumn{4}{|c}{ Source: own computations } \\
\hline
\end{tabular}

In Table 12, four sets of unstandardized linear discriminant coefficients are calculated, which will be used to classify new cases.

Table 12. Fisher's linear discriminant functions

\begin{tabular}{|c|c|c|c|c|}
\hline & \multicolumn{4}{|c|}{ HDI } \\
\cline { 2 - 5 } & 1 & 2 & 3 & 4 \\
\hline GDPperCap(PPP2011) & $4,349 \mathrm{E}-005$ &, 000 &, 000 &, 000 \\
Income Gini &, 647 &, 962 & 1,133 &, 979 \\
Wealth Gini &, 286 &, 309 &, 322 &, 298 \\
Poverty Rate &, 382 &, 075 &,- 159 &,- 167 \\
(Constant) & $-38,193$ & $-34,777$ & $-37,366$ & $-34,517$ \\
\hline
\end{tabular}

Source: own computations

These classification function coefficients create new discriminant function equations by group:

$\mathrm{G}_{\text {HDI }=\text { Low }}=-38.193+0.382 \times$ PovertyRate $+0.286 \times$ WealthGini+0.647xIncomeGini $+4.349 \times 10^{-}$

${ }^{0.05}$ xGDPperCap

$\mathrm{G}_{\text {HDI }}=$ Medium $=-34.777+0.075 x$ PovertyRate $+0.309 \times$ WealthGini $+0.962 x$ IncomeGini

$\mathrm{G}_{\text {HDI }=\text { High }}=-34.366-0.159 x$ PovertyRate+0.322xWealthGini+1.133xIncomeGini

$\mathrm{G}_{\mathrm{HDI}}=$ VeruHigh $=-34.517-0.167 \mathrm{xPovertyRate}+0.298 \mathrm{xWealthGini+0.979xIncomeGini}$

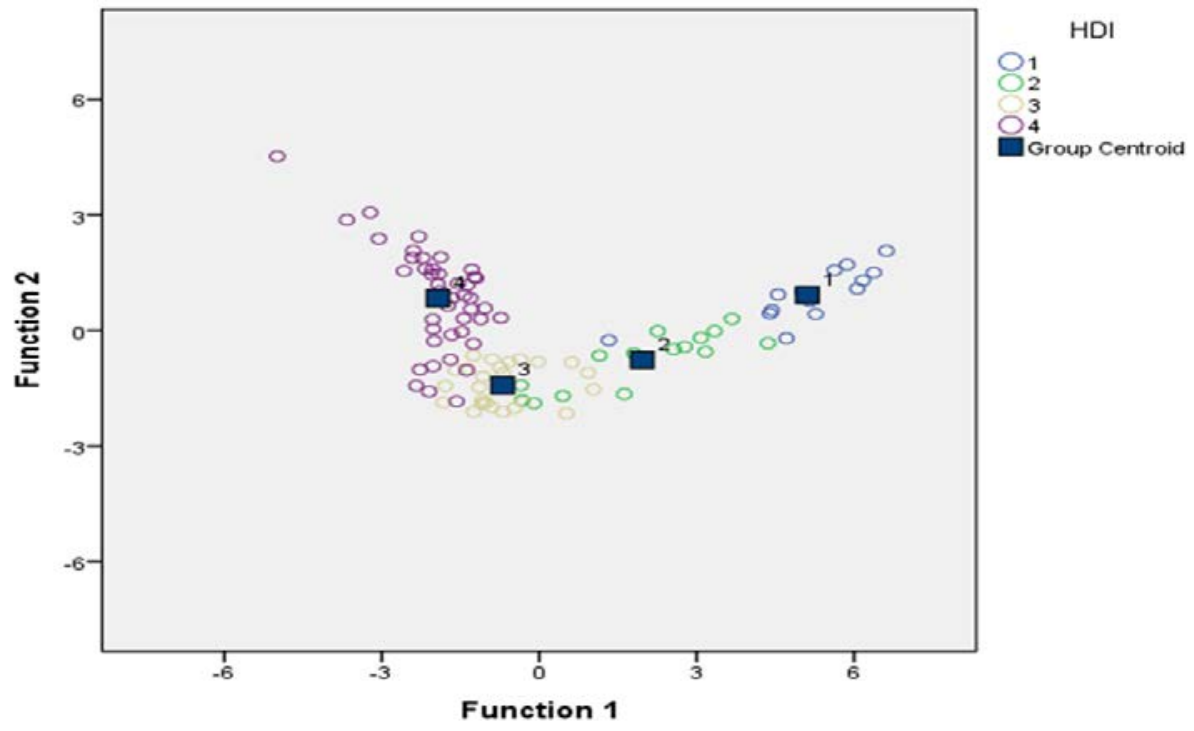

Figure 2. Canonical Discriminant Functions

Source: own computation 
In figure 2, the closer the group centroids, the more errors of classification will be. The figure shows that the classes are clearly separated in the orthogonal system of the first and the second discriminant functions. In Table 13, classification statistics assesses the efficiency of the discriminant functions and whether they work equally well for each group of variables. The bold numbers on the diagonal of the confusion matrix show the correct predictions for each category. Overall, $83.7 \%$ of countries were correctly classified.

Table 13. Classification results

\begin{tabular}{|c|c|c|c|c|c|c|c|}
\hline & & \multirow[t]{2}{*}{ HDI } & \multicolumn{4}{|c|}{ Predicted Group Membership } & \multirow{2}{*}{ Total } \\
\hline & & & 1 & 2 & 3 & 4 & \\
\hline \multirow{7}{*}{ Original } & \multirow{4}{*}{ Count } & 1 & 13 & 1 & $\overline{0}$ & 0 & 14 \\
\hline & & 2 & 2 & 9 & 4 & 0 & 15 \\
\hline & & 3 & 0 & 2 & 24 & 0 & 26 \\
\hline & & 4 & 0 & 0 & 6 & 37 & 43 \\
\hline & \multirow{4}{*}{$\%$} & 1 & 92,9 & 7,1 & 0 & 0 & 100,0 \\
\hline & & 2 & 13,3 & 60,0 & 26,7 & , & 100,0 \\
\hline & & 3 & ,0 & 7,7 & 92,3 & 0 & 100,0 \\
\hline \multirow{9}{*}{ Cross-validated ${ }^{\mathrm{b}}$} & & 4 & , 0 & , & 14,0 & 86,0 & 100,0 \\
\hline & & 1 & 13 & 1 & 0 & 0 & 14 \\
\hline & Count & 2 & 2 & 9 & 4 & 0 & 15 \\
\hline & (20uा & 3 & 0 & 2 & 24 & 0 & 26 \\
\hline & & 4 & 0 & 0 & 7 & 36 & 43 \\
\hline & \multirow{4}{*}{$\%$} & 1 & 92,9 & 7,1 & 0 & , & 100,0 \\
\hline & & 2 & 13,3 & 60,0 & 26,7 & , & 100,0 \\
\hline & & 3 &, 0 & 7,7 & 92,3 & 0 & 100,0 \\
\hline & & 4 & , & , & 16,3 & 83,7 & 100,0 \\
\hline & & & & & & & \\
\hline
\end{tabular}

Source: own computation

a. $84,7 \%$ of original grouped cases correctly classified.

b. Cross validation is done only for those cases in the analysis. In cross validation, each case is classified by the functions derived from all cases other than that case.

c. $83,7 \%$ of cross-validated grouped cases correctly classified.

The histogram of Figure 3 shows the shape of the distribution of the discriminant scores by groups. The histogram shows that there is no overlap among the groups, the distribution function spreads to the left and to the right, hence the first discriminant function discriminates best (Hans-Vaughn, 2017). These results are in accordance with the conclusions drawn from the interpretations of squared canonical correlations.

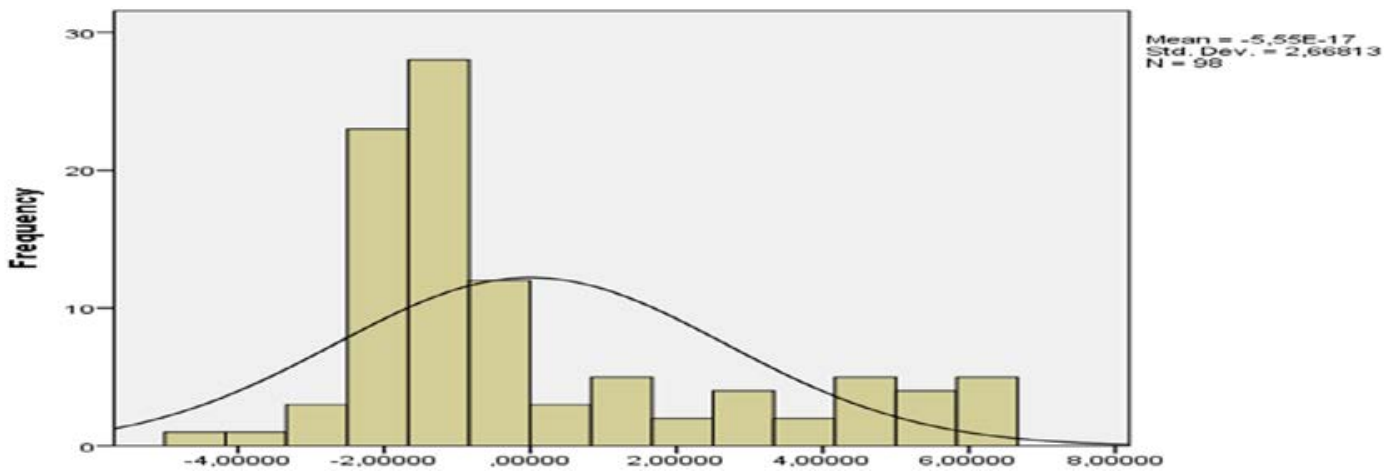

Figure 3. Discriminant Scores from Function 1

Source: own computation 


\section{CONCLUSIONS}

If we compare the MDA classifier with the multinomial logistic regression classifier applied on the same dataset (Georgescu et al., 2020), we conclude that the MLR model was somewhat more efficient, with an accuracy 92.9\% compared with the MDA accuracy of 83.7. Another result of the discriminant model is that overall, GDP per capita has no discriminative power; from three retained discriminant functions, the first one discriminates best. This study can be continued by the application of other machine learning classifiers, such as neural networks, naïve Bayes, K-Nearest neighbors, etc.

\section{ACKNOWLEDGMENT}

The paper is part of Ane-Mari Androniceanu's doctoral research program at the Doctoral School of Management at Bucharest University of Economic Studies.

\section{REFERENCES}

Androniceanu, A. \& Tvaronavičienė, M. (2019). Developing a holistic system for social assistance services based on effective and sustainable partnerships. Administratie si Management Public, 33, 103-118, DOI: 10.24818/amp/2019.33-06.

Belas, J., Kmecová, I., \& Cepel, M. (2020). Availability of human capital and the development of the public infrastructure in the context of business activities of SMEs. Administratie si Management Public, 34, 27-44. DOI: 10.24818/amp/2020.34-02

Bencsik, A., Juhasz, T., Mura, L., \& Csanadi, A. (2019). Impact of Informal Knowledge Sharing for Organizational Operation. Entrepreneurial Business and Economics Review, 7(3), 25-42. https://doi.org/10.15678/EBER.2019.070302

Bertan, S. (2020). Key Success Factors for Doing Business in Hot Air Balloon Riding. Journal of Tourism and Services, 20(11), 124-131. doi: 10.29036/jots.v11i20.131

Bian, H. (2012). SPSS Discriminant function analysis. Retrieved from http://kharazmi-statistics.ir/ Uploads/Public/MY\%20article/SPSS\%20Discriminant\%20Function\%20Analysis.pdf

Cohen, J. (1988). Statistical power analysis for the behavioural sciences. $2^{\text {nd }}$ Edition. Hillsdale, NJ: Lawrence Erlbaum.

Demirelişçi, B., Juknevičienë, V., \& Pukinskytë, S. (2020). The potential for regional development in the Baltic States: case study of regions with free economic zones. Forum Scientiae Oeconomia, 8(1), 49-66. DOI: 10.23762/fso_vol8_no1_4.

Dervis, K. \& Klugman, J. (2011). Measuring human progress: the contribution of the human development index and related indices. Revue d'Économie Politique, 121, 73-92.

Georgescu, I., Androniceanu, A., \& Kinnunen, J. (2018). A computational analysis of economic freedom indicators and GDP in EU States. Paper presented at the 17th International Conference on Informatics in Economy (IE 2018), Iasi, Romania, 17-20 May 2018, 461-468.

Georgescu, I. \& Kinnunen, J. (2019). Well-being and economic freedoms in OECD. In Rethinking Social Action. Core Values in Practice; Editura Lumen: Iasi, Romania, 2019; pp. 108-125.

Georgescu, I. \& Kinnunen, J. (2020). The digital effectiveness on economic inequality: a computational approach. In Business Revolution in A Digital Era; Dima, A.M., D’Ascenzo, F., Eds., forthcoming.

Georgescu, I., Kinnunen, J., Androniceanu, A., \& Androniceanu, A.-M. (2020). Global well-being and economic inequality. Paper presented at the $19^{\text {th }}$ International Conference on Information in Economy (IE 2020), 21-24 May 2020, 266-273. 
Haller, A. (2020). From classical and neoclassical economic growth to degrowth in Europe. Challenges for public administration. Administratie si Management Public, 34, 150-170. DOI: 10.24818/amp/2020.34-9

Hans-Vaughn, D. L. (2017). Applying multivariate statistical concepts. Routledge. New York

Ivanisevic, A., Losonc, A., Radisic, M., Njegovan, M., \& Pavlovic, A. (2020). Development of an effective planning model for improving financial performance. Forum Scientiae Oeconomia, 8(1), 67-81, DOI: https://doi.org/10.23762/FSO_VOL8_NO1_5

Katekhaye, D., Meyer, N., \& Magda, R. (2019). Entrepreneurial core motivation as a success factor for rural entrepreneurship in western India. Polish Journal of Management Studies, 19 (2), 218230.

Kinnunen, J., Androniceanu, A., \& Georgescu, I. (2019a). The role of economic and political features in classification of countries-in-transition by human development index. Informatica Economica, 23(4), 26-40.

Kinnunen, J., Androniceanu, A., \& Georgescu, I. (2019b). Impact of economic and political systems on Human Development Index: A Computational Evaluation, Paper presented at the 18th IE 2019 International Conference on Informatics in Economy, 30-31 May 2019, Bucharest, Romania, pp. 459-466.

Meyer, D. F. \& Meyer, N. (2020). The relationships between entrepreneurial factors and economic growth and development: The case of selected European countries. Polish Journal of Management Studies, 21 (2), 268-284.

Mishchuk, H., Samoliuk, N., Bilan, Y., \& Streimikiene, D. (2018). Income inequality and its consequences within the framework of social justice. Problemy Ekorozwoju, 13(2), 131-138.

Mura, L., Gontkovicova, B., Dulova Spisakova, E., \& Hajduova, Z. (2019). Position of Employee Benefits in Remuneration Structure. Transformations in Business \& Economics, 18, 2 (47), 56173.

Prakash, R. \& Garg, P. (2019). Comparative assessment of HDI with Composite Development Index (CDI). Insights into Regional Development, 1(1), 58-76. https://doi.org/10.9770/ird. 2019.1.1(5)

Ranasinghe, R. (2019). Antecedents of Job Performance of Tourism Graduates: Evidence from State University-Graduated Employees in Sri Lanka, Journal of Tourism and Services 10(18): 16-34. https://doi.org/10.29036/jots.v10i18.83

Selivanova-Fyodorova, N., Komarova, V., Lonska, J., \& Mietule, I. (2019). Differentiation of internal regions in the EU countries. Insights into Regional Development, 1(4), 370-384. https://doi.org/10.9770/ird.2019.1.4(7)

United Nations Human Development Report. (2019). Beyond income, beyond averages, beyond today: Inequalities in human development index in the $21^{\text {st }}$ century. Technical notes. http://hdr.undp.org/sites/default/files/hdr2019_technical_notes.pdf

Vasilyeva, T., Bagmet, K., Bilan, S., \& Seliga, R. (2020). Institutional development gap in the social sector: cross-country analysis. Economics and Sociology, 13(1), 271-294. doi:10.14254/2071-789X.2020/13-1/17

Walde, J. (2014). Discriminant analysis. Slides. Retrieved from: https://www.uibk.ac.at/statistics /personal/janettewalde/lehre/phd_biology/diskriminanzanalyse.pdf

Yalonetzky, G. (2011). Inequality-adjusted HDI. Slides. Retrieved from: http://www.ophi.org.uk/wp -content/uploads/IHDI-the-basics.pdf 